\title{
Achievable tolerances in robotic feature machining operations using a low-cost hexapod
}

\author{
J. D. Barnfather ${ }^{1}$ • M. J. Goodfellow ${ }^{2}$ T. Abram ${ }^{1}$
}

Received: 8 June 2017 / Accepted: 26 October 2017 / Published online: 10 November 2017

(C) The Author(s) 2017. This article is an open access publication

\begin{abstract}
Portable robotic machine tools potentially allow feature machining processes to be brought to large parts in various industries, creating an opportunity for capital expenditure and operating cost reduction. However, robots lack the machining capability of conventional equipment, which ultimately results in dimensional errors in parts. This work showcases a low-cost hexapod-based robotic machine tool and presents experimental research conducted to investigate how the widely researched robotic machining challenges, e.g. structural dynamics and kinematics, translate to achievable tolerance ranges in real-world production to highlight currently feasible applications and provide a context for considering technology improvements. Machining trials assess the total dimensional errors in the final part over multiple geometries. A key finding is error variation which is in the sub-millimetre range, although, in some cases, upper tolerance limits $<100 \mu \mathrm{m}$ are achieved. Practical challenges are also noted. Most significantly, it is demonstrated that dimensional machining error is mainly systematic in nature and therefore that the total error can be dramatically reduced with in situ measurement and compensation. Potential is therefore found to achieve a flexible, highperformance robotic machining capability despite complex and diverse underlying scientific challenges. Overall, the
\end{abstract}

\section{J. D. Barnfather}

joshbarnfather@gmail.com

1 The Department of Mechanical, Aerospace and Civil Engineering, The University of Manchester, Pariser Building, Sackville Street, Manchester M13 9PL, UK

2 Civil Nuclear, Rolls-Royce Plc., PO Box 2000, Raynesway, Derby, DE23 7XX, UK work presented highlights achievable tolerances in lowcost robotic machining and opportunities for improvement, also providing a practical benchmark useful for process selection.

Keywords Machining · Robot · Tolerance · Hexapod · Performance $\cdot$ Error

\section{Introduction}

Robots are attracting interest in the nuclear, oil and gas and aerospace industries for machining relatively small features on large parts without reliance on conventional, large machine tools. This potentially reduces capital expenditure and operational costs and avoids heavy lifting by bringing the machining process to the part rather than moving large components around manufacturing facilities, which causes a health and safety concern. As noted by Wang et al. in [1], this is possible due to the availability of high-accuracy large-volume metrology equipment, such as laser trackers and indoor GPS systems, for robot positioning around large components, which potentially leads to high accuracy of feature positions. A brief application case study can be found in [2], which is particularly relevant to nuclear power plant components with feature tolerances of $100 \mu \mathrm{m}$ to $5 \mathrm{~mm}$ for weld prep, weld dressing, instrumentation penetration, nozzle and manway geometry.

High-tolerance robotic machining of metals is a developing technology, competing with conventional machine tools that can achieve tolerances of single microns [3]. Robotic machining has a range of technical barriers associated with it, which must be overcome before economic benefits can be exploited. This investigation provides a valuable contribution to the development of robotic machining 
techniques by characterising known technical challenges in terms of the overall achievable tolerances. Achievable tolerance characterisation is novel because it encompasses all error-contributing phenomena, using low-cost equipment, rather than a single source as is typical in the literature.

For example, kinematic modelling is widely researched as a key issue in accurate robot manipulation because this relates the programmed end effector positions to joint rotations and actuator extensions. Robot kinematics are discussed by Weill et al., where dimensional errors in links and joints are noted to cause assembly misalignments and therefore differences between the nominal kinematic model, used in the controller, and the real world [4]. In unconventional parallel robot structures, which have a complex configuration of actuators and joints, such differences are due to difficulties in modelling the non-linear mapping between actuator and machining coordinate spaces [5]. This is problematic because parallel kinematic hexapod robots are desirable for machining due to their stiffness benefits [6-11].

Fassi and Wiens support kinematic modelling challenges but note that parallel robotic configurations have a noncumulative error stack up in links and joints, which theoretically provides improved accuracy compared to serialarm alternatives [12]. Agheli and Nategh discuss kinematic model calibration using a hexapod robot and find that optimum results are achieved when models are based on maximum observable robot error measurements, which are at the limits of the working envelope in this case [9]. This potentially introduces challenges in identifying the highest error levels in other robot configurations because Halaj and Kurekova conclude that positional errors vary over the working envelope [13].

As well as kinematic modelling issues, Fassi and Wiens highlight concerns over dynamic structural rigidity issues and their influence on part quality in robotic machining [12]. Zhang et al. note that the stiffness for a typical industrial robot is around $1 \mathrm{~N} / \mu \mathrm{m}$, whereas a typical machine tool has stiffness greater than $50 \mathrm{~N} / \mu \mathrm{m}$ and also expresses accuracy concerns for robotic machining due to machining forces and imperfect kinematic models [14]. This is supported by Doukas et al. who present experimental results on deflection behaviour [15]. Pandremenos et al. back up rigidity concerns further with experimental results highlighting accuracy and chatter issues [16]. In addition, joint stiffness is specifically discussed as an influence on part quality by Dumas et al., although data is difficult to obtain from robot manufacturers and user evaluation is recommended [17].

Work done by Sornmo et al. attempts to counteract rigidity problems with adaptive force control in robot machining, discussing how part inaccuracy is caused by excessive process forces that result in deviations from programmed paths [18]. Matsuoka et al. also highlight the importance of this issue by testing different machining strategies for best force management [19]. Lehmann et al. combine adaptive force control, strategy optimisation and off-line force compensation techniques for part accuracy improvement [20]. Olofsson et al. also consider machining force compensation by using a piezo-actuated micro-manipulator to compensate for tool deflection [21].

Further robotic machining literature is available that backs up kinematic and structural dynamic concerns. For example, the research of Abele et al. focuses on both the kinematic and stiffness modelling of a serial-arm robotic machine tool, highlighting dynamic differences from conventional machine tools and tool displacement problems [22]. Also, Bouzgarrou et al. and Li et al. follow a similar theme in the context of a parallel kinematic design robot [23, 24]. The influence of cutting force, structural rigidity and full kinematics compensation on robotic machining accuracy is, again, noted by $\mathrm{Wu}$ et al. and Pessi et al. [25-27]. Pan and Zhang expand on the issues mentioned by considering the impact of rigidity on low material removal rate and chatter, and implement a real-time compensation algorithm based on stiffness modelling to counteract this [28]. Work by Pan et al. relates cutting force and structural rigidity models to chatter issues in robotic machining, presenting stability criteria and highlighting the difference between conventional machine tool characteristics [29].

Conventional machine tool issues, including gear back lash and wear [30], are exaggerated in robotic machining due to structural differences [31]. Gong et al. also suggest that non-geometric robot errors should also be offset by accounting for thermal variations and joint flexibility under load [32]. Thermal concerns are supported by Kamrani et al. [33]. In research published by Antunes Simoes et al., the relationship between optimised process variable selection and the surface quality and dimensional error is highlighted, although this is in the context of robotic machining of plaster parts [34]. Olabi et al. highlights that trajectory planning is a key non-geometric contributor to path error [35], backed up by Zargarbashi et al. [36, 37]. This issue and robot feed rate accuracy, as assessed by Young and Pickin [38], are key research areas for improving machined surface quality. Chen and Dong show that robot repeatability decreases with reach and supports concerns over chatter, path planning, calibration and low material removal rates [39].

Overall, the robotic machining literature available highlights a complex and diverse range of research issues that result in poor part quality. This literature is well justified for tackling other challenges but it does not give a thorough insight into the combined overall impact that robotic machining downfalls have on achievable tolerances in real-world production. Here, a novel low-cost robotic machine tool is proposed using the Fanuc F200iB hexapod and achievable tolerance ranges are investigated for 
various geometries with machining trials. More specifically, the experimental investigation presented builds on the work of Tunc et al. [40-42] who assess dynamic stiffness variance of the same Fanuc F200iB hexapod robot over its working volume and the implications for machining accuracy.

The contribution made is the provision of practical data and analysis for use by manufacturers to improve low-cost industrial robot-based machine tools and to determine applications for current implementation. This is needed because the literature associated with specific issues contributing to dimensional errors does not completely provide this highlevel perspective alone. The intended impact is therefore to encourage development by highlighting applications where robotic machining can be feasibly adopted in addition to the scale of challenges. The results presented also serve as a benchmark for comparing technology improvements against, which is necessary to push robotic machining technology further. It therefore allows advances associated with individual error contributors to be considered in the context of a key high-level problem.

An account of work done is presented beginning with definitions of terms and the analysis procedure used in Section 2. An overview of the equipment used, details of the experimental set-up and methodology are then given in Sections 3 and 4, respectively. Finally, data is analysed to determine machining performance indices in Section 5 and findings are summarised in Section 6.

\section{Definitions and theory}

This section describes the definitions and theory associated with the experiments in Section 2.1 and analysing the data acquired in Section 2.2.

\subsection{Machining parameters}

Spindle speed, $N$ in RPM, for maximum stable machining efficiency is determined through modal analysis, as explained in the Section 3. $N$ is related to feed rate, $v_{\mathrm{f}}$ in millimetres per minute, using Eq. 1, where $f_{\mathrm{z}}$ is the chip load per tooth in millimetres, taken from tool manufacturer recommendations, and $z_{\mathrm{c}}$ is the number of tool teeth.

$v_{\mathrm{f}}=f_{\mathrm{z}} \times N \times z_{\mathrm{c}}$

Material removal rate, $Q$ in cubic centimetres per minute, is given by Eq. 2, where $a_{\mathrm{p}}$ is the axial depth of cut in millimetres and $a_{\mathrm{e}}$ is the radial depth of cut in millimetre, also determined through modal analysis.

$Q=\frac{a_{\mathrm{p}} \times a_{\mathrm{e}} \times v_{\mathrm{f}}}{1000}$
The tool life criterion used to approximate useful tool cutting time, $T$ in minutes, before degradation occurs to the degree that the tool can no longer cut required dimensions, is defined as a uniform flank wear land, VB, of $0.3 \mathrm{~mm}$ averaged over all teeth in dry cutting conditions. This criterion is recommended by ISO 8688-2 [43] and is estimated according to Taylor method [44]. Taylor tool life estimation is widely utilised and recommended in various works [45-50]. Wang et al. support the idea that tool life can be estimated in robotic machining when stable cutting parameters are established [51], i.e. with modal analysis. Tool life estimates are qualitatively verified by the operator with regular visual tool inspection in between operations and by listening for changes in machining noise.

$T$ is given by the following equations [48]. $n$ is Taylor tool life exponent and is computed from reference tool lives, $T_{\mathrm{RA}}$ and $T_{\mathrm{RB}}$, at the extreme upper and lower ranges for a given tool, which correspond to the reference cutting speeds $v_{\mathrm{cRA}}$ and $v_{\mathrm{cRB}}$ in metres per minute. These reference values are provided for each tool by their manufacturer in dry cutting conditions. $C$ is the Taylor constant and computed using $n$ and $v_{\text {cRA }}$. Finally, $T$ for the real cutting conditions used in experiments is estimated using Eq. 5, where $v_{\mathrm{c}}$ is the cutting speed dependent on the cutting diameter at $a_{\mathrm{p}}, D_{\text {cap }}$, determined through modal analysis of the specific robot and tool set-up.

$n=\frac{\ln v_{\mathrm{cRB}}-\ln v_{\mathrm{cRA}}}{\ln T_{\mathrm{RA}}-\ln T_{\mathrm{RB}}}$

$C=v_{\mathrm{cRA}} \times T_{\mathrm{RA}}^{n}$

$T=\left(\frac{C}{v_{\mathrm{c}}}\right)^{1 / n}$

$v_{\mathrm{c}}=\frac{D_{\text {cap }} \times \pi \times N}{1000}$

\subsection{Experimental data analysis}

Experimental data analysis theory is based on previous work done to develop a robotic machine tool performance evaluation methodology based on standards published on robotics and machining independently [2]. Interested readers are directed to this paper for detailed information on the theory used.

In machining trials, the upper machine performance index, $\hat{P}_{\mathrm{mkU}}$, is estimated with a confidence interval to judge the ability of the process to achieve upper tolerances limits according to methods described in [2]. A prerequisite to index computation is to plot errors between nominal and measured dimensions with a run chart to assess 
statistical control, where instability is indicated by stepped variation. Non-normally distributed data may occur due to outliers, process variables shifts, biases and process limits or because it has a different distribution. To determine the specific estimation method for $\hat{P}_{\mathrm{mkU}}$, distribution class is assessed to check for normality, which is indicated graphically using histograms with fitted ideal normal distribution curves and using normality tests when sample size is $\geq 30$, as recommended by Razali et al. [52].

The Anderson-Darling normality test is chosen because it achieved a consistently high statistical power in the Razali et al. study in comparison to alternatives. Normality tests reject the null hypothesis that the data is normally distributed if the estimated probability, $P$ value, of computing the test statistic, $A^{2}$, for a normal distribution is $\leq 0.05$. The $P$ value is determined from critical values of $A^{2}[53,54]$.

In cases where a normal distribution is not observed, data is transformed using the Box-Cox method [55], as recommended by Hosseinifard et al. [56]. To do this, each individual value from the dataset, $y_{i}$, is raised to the power of $\lambda$, which is found by searching for the optimum value between -5 and 5 to achieve normality according to $A^{2}$, excluding zero where the natural logarithm of the dataset is taken. If transformation is unsuccessful, alternate computation methods are used as specified in the key reference given above [2].

$y_{i}^{(\lambda)}=\left\{\begin{array}{cc}\frac{y_{i}^{\lambda}-1}{\lambda} ; & \lambda \neq 0 \\ \log y_{i} ; & \lambda=0\end{array}\right.$

In analysis of variance (ANOVA) tables plotted on graphs, the 'Groups' row contains analysis statistics for testing variation between data groups and the 'Error' row contains analysis statistics for testing variation within data groups. For both rows, the sum of squares of the observations is given by SS, the degrees of freedom is given by df and the ratio between SS and df is given by the mean squared error, MS. The ratio between MS for each variation source is given by the F-statistic, $F$. The probability of $F$ actually being higher is given by Prob $>F$ and indicates a significant difference between data groups when it has a value $\leq 0.05$.

\section{Equipment and set-up}

The following sub-sections describe the equipment and setup procedures used to conduct experiments. This begins with a description of the robotic machine tool proposed and tested in Section 3.1 and then its alignment and positioning procedures in Section 3.2. Test geometry, tooling and programming details are given in Sections 3.3-3.5.

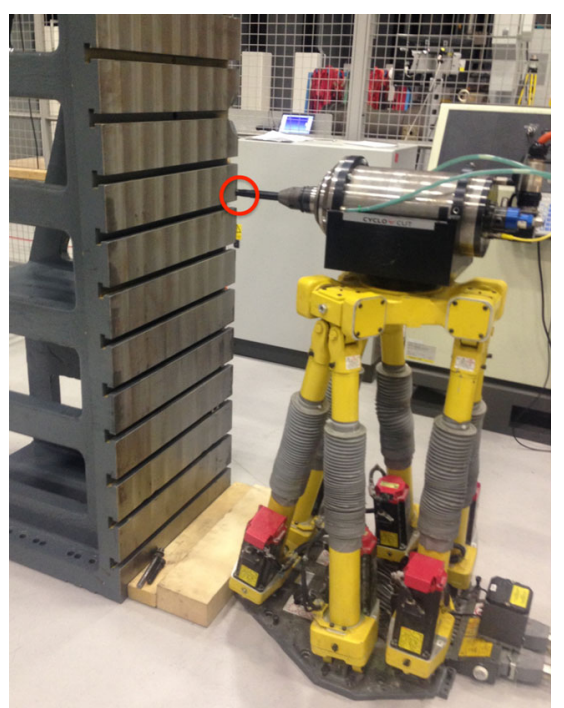

Fig. 1 Robotic machining set-up with the tool centre point highlighted by the red circle

\subsection{Robotic machine tool}

As shown in Fig 1, the robot used for performance investigation is a Fanuc F200iB hexapod controlled by the Fanuc $\mathrm{R}-30 \mathrm{iA}$ controller. This has a six-degree-of-freedom parallel kinematic design with stiffness and geometric error accumulation benefits over serial-arm alternatives [12, 27]. The robot manipulates an 8-KW Gamfior machining spindle and uses a T-slotted vertical fixture as a machine bed, where plate material is mounted using finger clamps. An example of this is seen in Fig. 2.

\subsection{Alignment and positioning}

For machining trials, robot axes are aligned to be parallel and square to the fixture using a dial test indicator (DTI) mounted in the spindle. In this procedure, the robot is first traversed along its $X$ and $Y$-axes in its working frame with

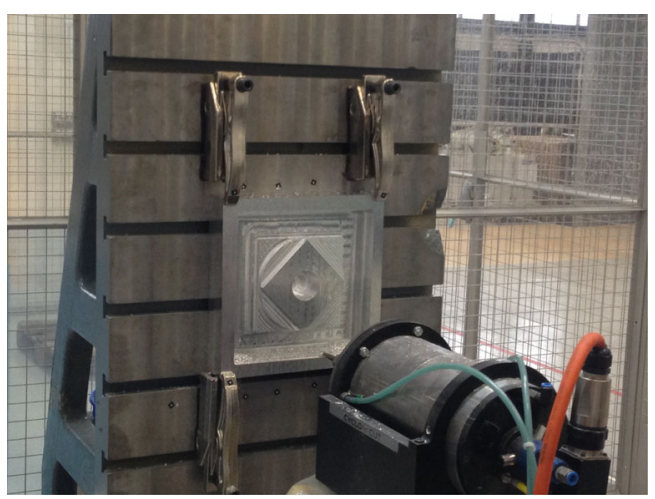

Fig. 2 Robotic machining set-up with work-piece mounted on the fixture with finger clamps 
the indicator pressed against the fixture. Non-parallelism is detected when values on the DTI are not constant during these motions. Corrections are made by manually adjusting the working frame rotations to achieve a constant indicator reading during traverse motions.

Squareness is corrected by manually rotating the DTI in the spindle, with it offset from the centre of rotation and pressed on the fixture, to trace out a circular path. The spindle is shown not to be square to the fixture if values indicated are not constant. Squareness corrections are made by manually adjusting the tool frame rotations, which relates the robot world coordinate system to the end effector. The overall alignment quality is limited by the flatness of the fixture and the uncertainty of the DTI.

To position the robot origin at the part origin, the Leica AT401 laser tracker is used. The process is summarised in Fig. 3 and involves fitting planes to measurement points taken on the face and sides of the plate to be machined and fitting a coordinate system at their intersection. The robot is then measured in this coordinate system, with the tracker's SMR mounted in the robot's spindle as its tool centre point. The result is a coordinate that is used to translate the robot to the part origin, where its working frame origin is set after adjustments are made to account for tool length.

\subsection{Machining test geometry}

Three artefacts are machined from aluminium in experiments, which contain features representative of those on large components. Aluminium is not necessarily universally relevant for all industries and applications but it can be efficiently machined in comparison to steels, for example, which, at the current state of low-cost robotic machining technology, is impractically time-consuming due to the shallow depths of cut necessary to avoid excessive tool wear

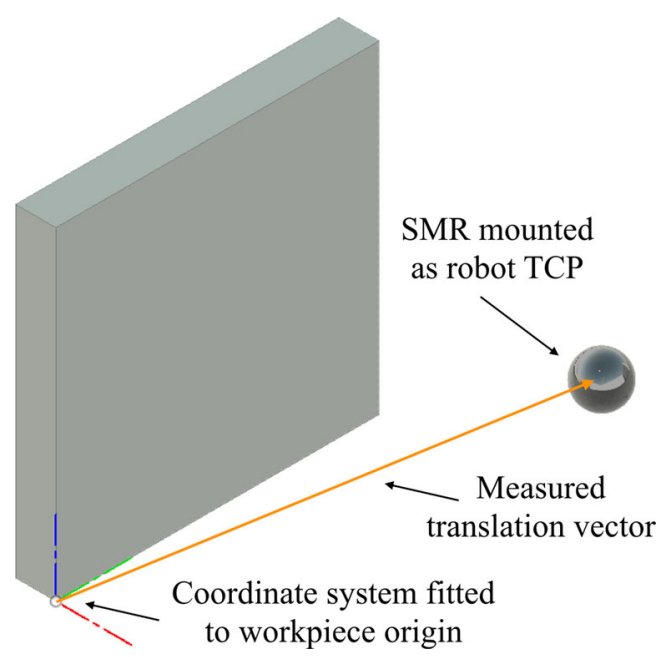

Fig. 3 Positional alignment diagram and complete failure. Test results presented in [42] indicate that axial cut depths would not exceed $250 \mu \mathrm{m}$ at a $60 \%$ radial cutting engagement, although this is dependent on a range of dynamic conditions including tool length, spindle speed and stiffness i.e. extension of robot actuators and position in working envelope [57-60]. This challenge is partly due to its being impractical to use as coolant in robotic machining as operations are conducted in an open environment, subjecting the process to higher than ideal cutting forces [61]. Aluminium is appropriate as it allows a robotic machine tool performance reference to be defined, using complex geometry, for comparing improvements against in the future, regardless of other challenges.

Potential applications for robotic feature machining on large components are as follows. These are inspired by the nuclear industry, although the primitive geometry types, i.e. lines, planes and circles/arcs, are common to most conceivable features on engineered components.

- Nozzle opening boring on vessels

- Nozzle weld preparation geometry

- Facing off welded nozzle blanks for hydrostatic testing

- Weld dressing

- Instrumentation bores

- Manways

- Mating surfaces between vessel faces

- Tube sheet baffle slots

Ideally, a robotic machine tool performance study would test geometry that is common to such features and include large enough combination of bores, radii, angled cuts, flat surfaces, straight profiles and circular profiles to draw statistically significant conclusions on. Test artefacts are chosen to assess flexible machining performance in a varied range of relevant situations and are shown in Figs. 4, 5 and 6. These are inspected with a Hexagon Metrology Global Silver 7107 CMM with a calibration uncertainty of $1.5 \mu \mathrm{m}+3 \mu \mathrm{m}$ per metre, defined according to ISO 10360-2 [62].

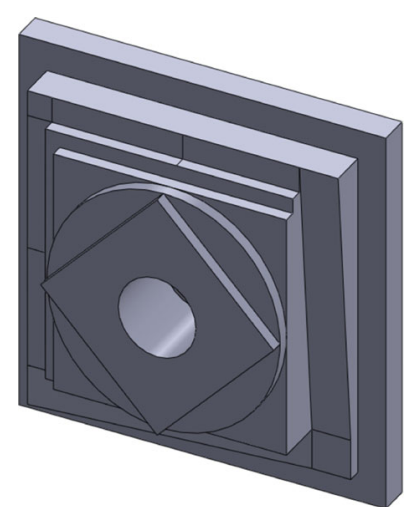

Fig. 4 NAS 979 machine tool test artefact. $\sim 200 \times 200 \times 50 \mathrm{~mm}$ 


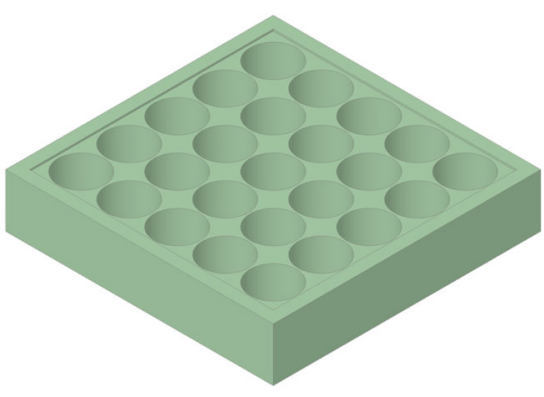

Fig. 5 Cylindrical pocket test artefact. $\sim 270 \times 270 \times 60 \mathrm{~mm}$

The primary artefact used to assess generic performance in flexible three-axis flexible machining is the NAS 979 Machine Tool Test Artefact [63], which tests the impact of the robot, control system and spindle on error over multiple geometric conditions.

To assess ability to machine cylindrical geometry over the working envelope of the robot, the Cylindrical Pocket Test Artefact is machined, which contains 25 cylinders, each measuring 50-mm $\varnothing$ with a 53-mm depth. Here, diameters at various cylinder depths and cylindricity are measured to gage performance. This is custom designed and not associated with a standard.

Finally, a test artefact composed of 20 weld prepared nozzles is used, each measuring $47.78-\mathrm{mm} \varnothing$ overall with a 25-mm $\varnothing$ internal bore and a 15-mm depth. Alongside the Cylindrical Pocket Test Artefact, a wide range of feature positions, depths, flatness, diameters, cylindricity, perpendicularity, parallelism, radii and angularity are machined. Overall, the artefacts cover geometry common to many feature machining operations on large components, making conclusions drawn using them for performance studies useful in a wide range of scenarios.

\subsection{Tooling and parameters}

Tooling is recommended and supplied by Sandvik Coromant, according to specific machining strategies as tabulated with machining parameters in Tables 1 and 2 .

Tool setting is done manually using the robot controllers built-in tool centre point teaching facility. This involves

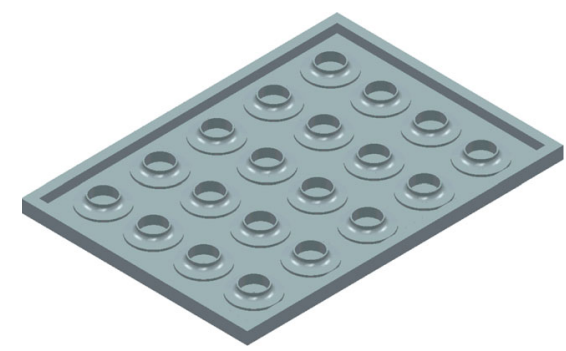

Fig. 6 Nozzle test artefact. $\sim 300 \times 240 \times 20 \mathrm{~mm}$ mounting a turned spike in place of a cutting tool in the robots spindle and directing the robot to point the spikes tip at a fixed point from three different orientations. This computes values for the tool frame position, i.e. the tool centre point. Every time a tool is changed, the $Z$ coordinate of the tool frame must be offset by the difference between the tool length and the length of turned spike to teach the original value.

Prior to CAM programming, axial and radial cut depth and spindle speed are selected based on stability limits for each tool using modal analysis i.e. tap testing. Modal analysis quantifies structural dynamic characteristics of the machine tool by measuring unique vibration signatures resulting from hammer impacts to determine frequency response functions (FRF). Responses enable stability lobes to be plotted and highlight low-resonance cut depth regions for given spindle speeds, making it possible to tune parameters for the highest material removal rate without chatter for a given tool, tool overhang length and tool holder [64-66].

Stability lobes were determined for each tool used according to the methodology discussed in the work of Tunc et al. [40-42], which experimentally investigates robotic machining dynamics and stable cutting parameters using the exact same robot and some of the same tools used here. This work should be consulted for a deeper insight into the procedure for estimating optimum cutting parameters.

\subsection{CAM programming}

Robot programming is done using Delcam PowerMILL with the Robot Interface plug-in, which allows tool paths to be calculated, simulated and programmed. Point-to-point programming was necessary, even when circular interpolation is justified, due to limited support for parallel kinematic robots in the CAM software. Improved CAM support is therefore a practical opportunity for reducing programme sizes and potentially improving accuracy in circular geometry. Nevertheless, programmes are written as conventional $\mathrm{NC}$ files and then converted into robot language and formatted. When programmes exceed $\sim 11,000$, it is also necessary to split them into smaller programmes due to controller storage restrictions. Finally, programmes are converted into the Fanuc .TP binary format for execution.

\section{Methodology}

As with Section 2.2, the methodology used to conduct experiments is based on previous work done to develop a robotic machine tool performance evaluation methodology, which can be accessed at [2]. 
Table 1 Cutting tool parameters

\begin{tabular}{llllllllll}
\hline Tool & $N \mathrm{RPM}$ & $f_{\mathrm{z}}(\mathrm{mm})$ & $v_{\mathrm{f}}(\mathrm{mm} / \mathrm{min})$ & $a_{\mathrm{e}}(\mathrm{mm})$ & $a_{\mathrm{p}}(\mathrm{mm})$ & $v_{\mathrm{c}}(\mathrm{m} / \mathrm{min})$ & $T(\mathrm{~h})$ & $\mathrm{Stage}$ & $Q\left(\mathrm{~cm}^{3} / \mathrm{min}\right)$ \\
\hline 25-mm CoroMill 390 end-mill & 3700 & 0.18 & 1332.0 & 15.0 & 0.35 & 290.597 & $\sim 3.0$ & $\mathrm{R}$ & 6.993 \\
16-mm CoroMill 390 end-mill & 5300 & 0.15 & 1590.0 & 9.6 & 1.5 & 266.407 & $\sim 3.0$ & $\mathrm{R} \& \mathrm{SF}$ & 22.896 \\
5-mm CoroMill Plura end-mill & 5500 & 0.0657 & 1084.05 & 3.0 & 0.4 & 86.394 & $\sim 18.0$ & $\mathrm{SF}$ & 1.301 \\
10-mm CoroMill Plura end-mill & 5500 & 0.16 & 3520.0 & 6.0 & 0.4 & 172.788 & $\sim 8.0$ & $\mathrm{SF}$ & 8.448 \\
18-mm CoroMill Plura end-mill & 5500 & 0.282 & 3102.0 & 10.8 & 0.5 & 311.018 & $\sim 8.0$ & $\mathrm{SF}$ & 16.751 \\
5-mm CoroMill Plura end-mill & 5500 & 0.0657 & 1084.05 & 3.0 & 0.1 & 86.394 & $\sim 15.0$ & $\mathrm{FF}$ & 0.325 \\
10-mm CoroMill Plura end-mill & 5500 & 0.16 & 3520.0 & 6.0 & 0.1 & 172.788 & $\sim 8.0$ & $\mathrm{FF}$ & 2.112 \\
5-mm CoroMill Plura ball-nose & 5500 & 0.147 & 1617.0 & 3.0 & 0.1 & 86.394 & $\sim 5.0$ & $\mathrm{FF}$ & 0.485 \\
18-mm CoroMill Plura end-mill & 5500 & 0.282 & 3102.0 & 10.8 & 0.1 & 311.018 & $\sim 8.0$ & $\mathrm{FF}$ & 3.35 \\
\hline
\end{tabular}

Note that in finishing operations, $a_{\mathrm{e}}$ is a maximum value as the material thickness left from roughing only allows this to be fully reached during floor machining operations whereas only up to $0.4 \mathrm{~mm}$ of material is available to cut on walls (nominally). Using maximum parameter values in computations allows $T$ to be estimated conservatively

As summarised in Table 2, the procedure for running the machining trial programmes for each test artefact are similar. Each begins with a roughing stage $(R)$ that leaves a material thickness of $0.5 \mathrm{~mm}$, and then goes onto semifinishing (SF) which leaves a material thickness of $0.1 \mathrm{~mm}$ before final finishing (FF). Unused tools/inserts are used for each artefact and are selected dependent on geometry, as summarised in Tables 1 and 2. Each tool is mounted using a Sandvik Hydro-Grip tool holder with adaptive collets where necessary, excluding the 16-mm $\varnothing$ Coromill 390 indexable end-mill, which has a threaded coupling to a HSK 63A tool holder to increase stiffness during roughing. Tool parameters reflect the dynamic stability of each tool setup, determined with modal analysis, although in finishing stages radial cut depths can be very low on wall geometry, given that most of the material is already removed.

For the Cylindrical Pocket Test Artefact, stock was faced off initially to create a reference surface for inspection and then the main roughing operations were performed with the CoroMill 390 25-mm $\varnothing$ indexable end-mill, with new inserts for each pocket in this case, which has a length suitable for the cylinder depths. Tool retraction moves were included in roughing programmes for material removal, tool cooling and chip adherence prevention. Semi-finishing and finishing operations were done using an extended cut length Coromill Plura 18-mm $\varnothing$ end-mill. Whilst necessary for collision avoidance, this combination of factors results in less stability, which is why $Q$ is low despite relatively high

Table 2 Machining times for each artefact, stage and tool used

\begin{tabular}{lll}
\hline Artefact and stage & Tool & $\begin{array}{l}\text { Machining time (h:min:s) per } \\
\text { feature (total) }\end{array}$ \\
\hline \multicolumn{1}{c}{ NAS artefact } & & $(02: 03: 55)$ \\
R & $16-\mathrm{mm}-\varnothing$ CoroMill 390 indexable end-mill & $(00: 46: 42)$ \\
SF & $16-\mathrm{mm}-\varnothing$ CoroMill 390 indexable end-mill & $(02: 34: 14)$ \\
F & $18-\mathrm{mm}-\varnothing$ Coromill Plura end-mill & $00: 18: 50(07: 50: 50)$ \\
$\quad$ Cylindrical pocket artefact & & $00: 04: 59(02: 04: 35)$ \\
R & $25-\mathrm{mm}-\varnothing$ CoroMill 390 indexable end-mill & $00: 05: 08(02: 08: 20)$ \\
SF & $18-\mathrm{mm}-\varnothing$ Coromill Plura end-mill \\
F & $18-\mathrm{mm}-\varnothing$ Coromill Plura end-mill & $00: 03: 30(01: 10: 06)$ \\
Nozzle artefact & & $00: 00: 50(00: 16: 42)$ \\
R & $16-\mathrm{mm}-\varnothing$ CoroMill 390 indexable end-mill & $00: 01: 39(00: 32: 59)$ \\
SF & $10-\mathrm{mm}-\varnothing$ Coromill Plura end-mill & $00: 00: 47(00: 15: 30)$ \\
F & $10-\mathrm{mm}-\varnothing$ Coromill Plura end-mill & $00: 00: 34(00: 11: 23)$ \\
SF & $5-\mathrm{mm}-\varnothing$ Coromill Plura end-mill & $00: 01: 55(00: 38: 37)$ \\
F & $5-\mathrm{mm}-\varnothing$ Coromill Plura end-mill & \\
F & $5-\mathrm{mm}-\varnothing$ Coromill Plura ball-nose &
\end{tabular}


tool diameters. In contrast to this, operations performed using the 16-mm $\varnothing$ CoroMill 390 indexable end-mill are highly stable, achieving high values for $Q$, due to the tools shorter length and threaded interface with the tool holder.

For each artefact, stage and tool, Tables 1 and 2 show that machining time does not exceed estimated tool life. This is qualitatively verified by the operator during machining by listening for tool wear and visually inspecting tools.

In this investigation, variables associated with cutting forces, temperature, vibration, chip formation etc. are not monitored. This is because the aim of this work is to build on the available robotic machining literature by exploring the overall dimensional tolerances achievable despite the complex contributing phenomena that is already well studied. Expanding experiments and analysis to robustly ascertain specific origins of a given error is therefore likely to add little to the field, as summarised in Section 1.

\section{Results}

This section presents and discusses experimental results and analysis conducted to assess robotic machining process performance. The NAS 979 Machine Tool Test Artefact is considered in Section 5.1, the Cylindrical Pocket Test Artefact is considered in Section 5.2 and the Nozzle Test Artefact is considered in Section 5.3.

\subsection{NAS 979 machining trials}

Errors between measured and nominal dimensions are plotted in approximate machining order for the NAS 979 Machine Tool Test Artefact in Fig. 7, as stipulated in the standards that the theoretical analysis methodology, summarised in Section 2, is based upon. Further details of this

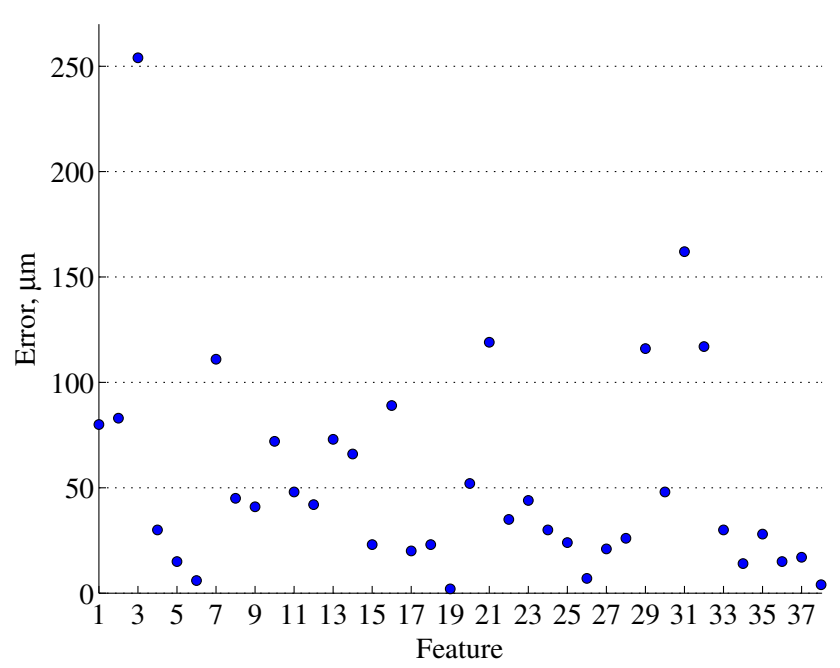

Fig. 7 NAS artefact feature error run chart

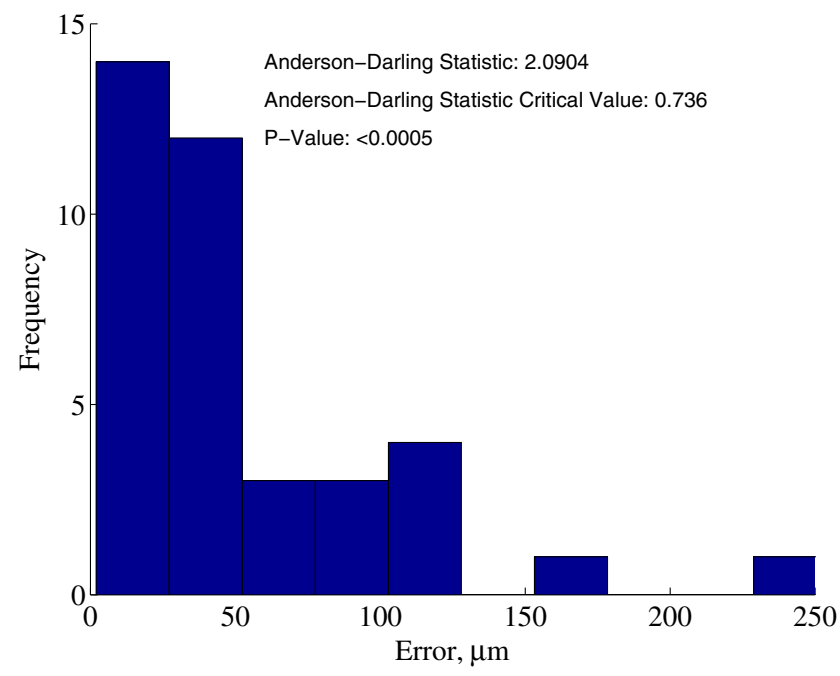

Fig. 8 NAS artefact error histogram

can be found in [2]. With this artefact, the aim is to quantitatively assess performance over multiple conditions, thereby allowing judgements to be made on the ability to flexibly use low-cost robotic machine tools in complex machining operations. Measurements of different geometrical errors are therefore analysed together as they each have an ideal value of zero. This means that, if the technology is robust, all errors should be consistently low, regardless of differences between the features they originate from.

Specific features referenced are listed below, which correspond to the Fig. $7 X$-axis labels, and highlight that some errors do not have a machining order as they are inherent properties of geometric elements. For example, it is meaningless to assign a machining order to bore diameter, perpendicularity and cylindricity as they are measured as

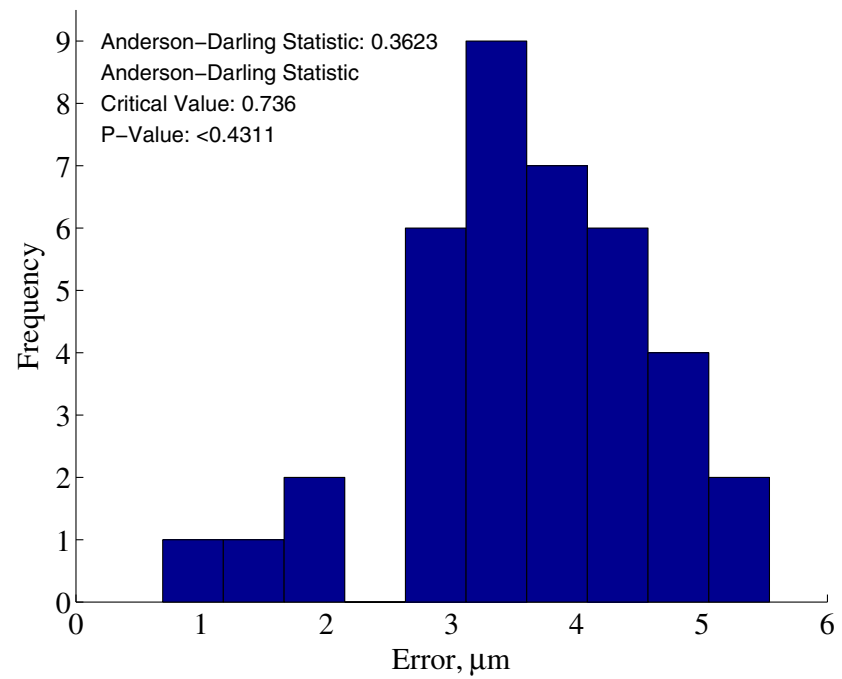

Fig. 9 Transformed NAS artefact error histogram 
a property of a single bore that was completed at a single instant in time.

1. Bore diameter

2. Bore perpendicularity

3. Bore cylindricity

4. Circle face depth

5. Top-square face depth

6. Mid-square face depth

7. Bottom-square plane depth

8. Bore face depth

9. Base face depth

10. Diamond side 1 to 2 perpendicularity

11. Diamond side 2 to 3 perpendicularity

12. Diamond side 3 to 4 perpendicularity

13. Diamond side 4 to 1 perpendicularity

14. Diamond side 1 to 3 parallelism

15. Diamond side 2 to 4 parallelism

16. Diamond side 1 to 3 distance

17. Diamond side 2 to 4 distance

18. Diamond angle

19. Top-square side to large side distance

20. Mid-square side to large side distance

21. Bottom-square side to large side distance

22. Circle face parallelism to diamond face

23. Top-square face parallelism to diamond face

24. Mid-square face parallelism to diamond face

25. Bottom-square face parallelism to diamond face

26. Bore face parallelism to diamond face

27. Outer square side A to B perpendicularity

28. Outer square side $\mathrm{B}$ to $\mathrm{C}$ perpendicularity

29. Outer square side $C$ to $D$ perpendicularity

30. Outer square side D to A perpendicularity

31. Outer square side A to $\mathrm{C}$ parallelism

32. Outer square side B to D parallelism

33. Diamond face flatness
34. Circle face flatness

35. Top-square face flatness

36. Mid-square face flatness

37. Bottom-square face flatness

38. Bore face flatness

No trend or stepped variation in machining errors is apparent, which fulfils the initial assumption for performance index computation. This is expected because no specific feature machining operations are repeated as this artefact explores generic performance in a varied range of conditions.

Normality assumptions are shown to be violated in Fig. 8, justifying transformation to correct skewness and meet prerequisites for performance index and confidence interval computation. Skewness is due to the zero limit of errors as they are computed to be absolute rather than directional to be judged alongside flatness, perpendicularity, parallelism and cylindricity. Successfully transformed error data is shown in Fig. 9 and used for index computation.

Upper machine performance indices and confidence intervals are plotted in Fig. 10 for a range of upper tolerance limits. A logarithmic relationship is apparent due to the transformation, although this does not invalidate index computations [67]. At a confidence of 95\%, 9.34-23.58\% of dimensional errors will exceed the upper specification limit set at $100 \mu \mathrm{m}$ and $0.01-1.6 \%$ will exceed the limit when set at $1000 \mu \mathrm{m}$ [68]. Further insight into how errors relate to robot problem areas may be drawn by repeating the machining process, which justifies consideration of repeated cylindrical and nozzle geometry in Sections 5.2 and 5.3.

\subsection{Cylindrical pocket machining trials}

Errors are plotted over time for each of the ten Cylindrical Pocket Test Artefact features in Fig. 11, as stipulated in
Fig. 10 NAS error performance indices

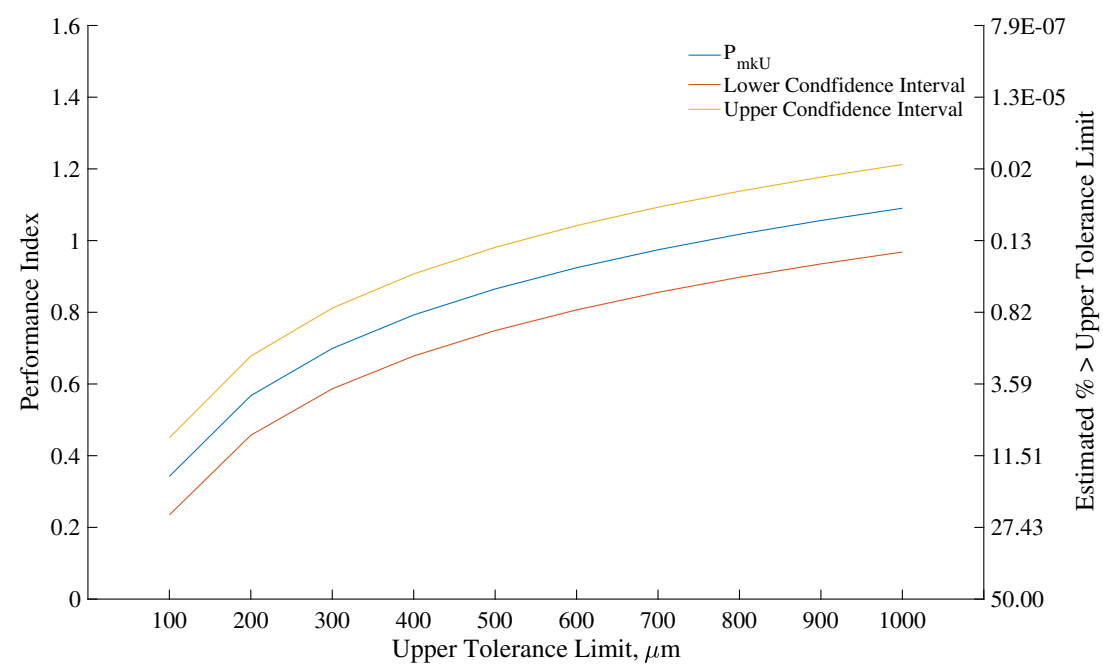




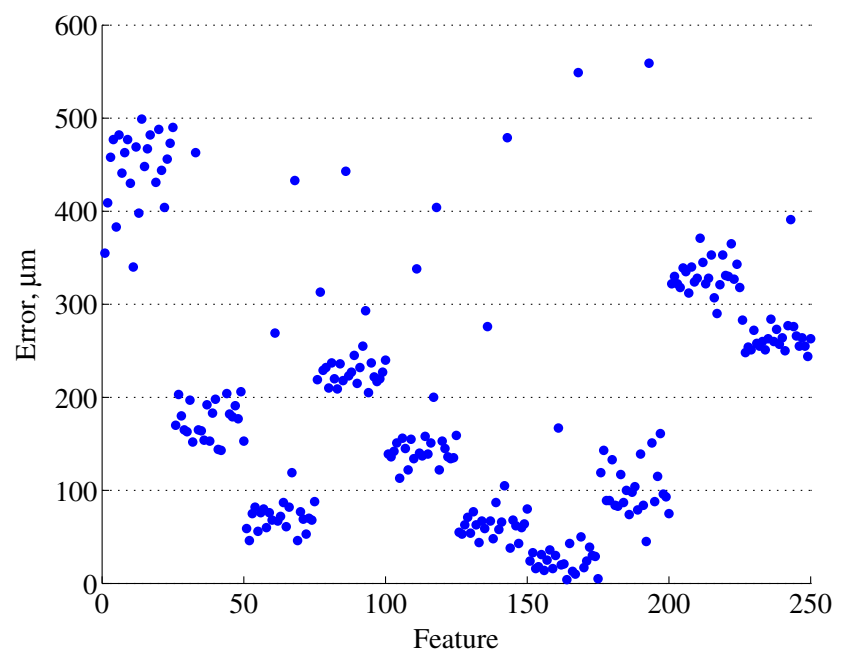

Fig. 11 Cylinder artefact feature error run chart

[2], i.e. Feature ${ }_{1}$ Cylinder $_{1 \ldots 25}$ to Feature ${ }_{10}$, Cylinder ${ }_{1 \ldots 25}$. These features are given in the $X$-axis labels of Fig. 13 . Whilst features are labelled with numbers, in reality, they do not have a meaningful machining order as they are mostly inherent in a completed cylinder, rather than sequentially machined. Clusters of data points in Fig. 11 indicate systematic error variation during machining between each feature and therefore a non-normal error distribution across the whole artefact, shown in Fig. 12.

For each feature, i.e. step or cluster of data points in Fig. 11, statistical control is suggested by random variation, although outliers are evident. Outlier cylinders are selected and removed for each feature measured. This is done by searching for the required multiple of standard deviations from the mean to create an inlier threshold that maximises that amount of data kept to achieve a normal distribution. Results of this are shown in Fig. 13. Normality tests are

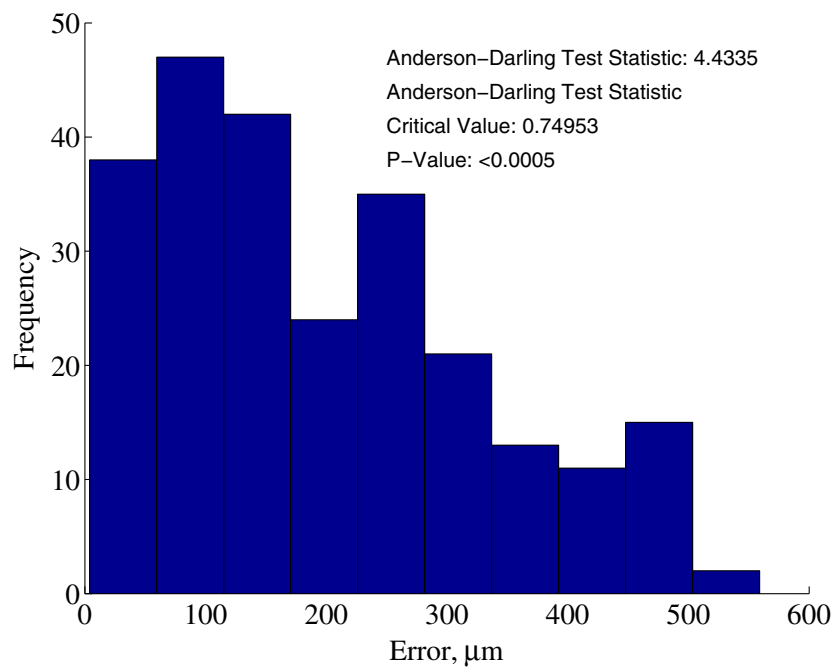

Fig. 12 Cylinder artefact feature error histogram

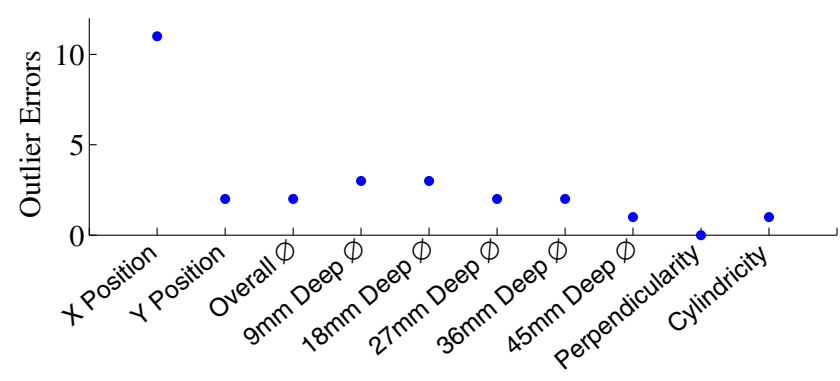

Fig. 13 Outlier removal results

run after outlier removal, proving each feature's error data to be normally distributed. Outlier removal therefore allows assumptions for performance index and confidence interval computation to be met for each feature, which was not the case initially.

Results show that most features have few outlier errors, despite a total of 27. Excessive outliers are observed in cylinder $X$-axis positions, suggesting that data is inherently non-normally distributed and therefore that transformation is more appropriate, for this feature, to fulfil requirements for performance index computation. This is done successfully.

Cylinders 21 and 25 contribute the most outlier errors, totalling 9 and 5, respectively, suggesting a systematic change in process dynamics that is not typical in comparison with cylinder errors in other areas of the working volume. Variance over the working envelope is supported as being feasible in the initial literature review and prior experimental work done to quantify positional error [69] and to measure deflection and dynamic stiffness for cutting parameter selection [40-42]. The excessive presence of outliers casts doubt over validity of remaining data from these cylinders so they are eliminated entirely.

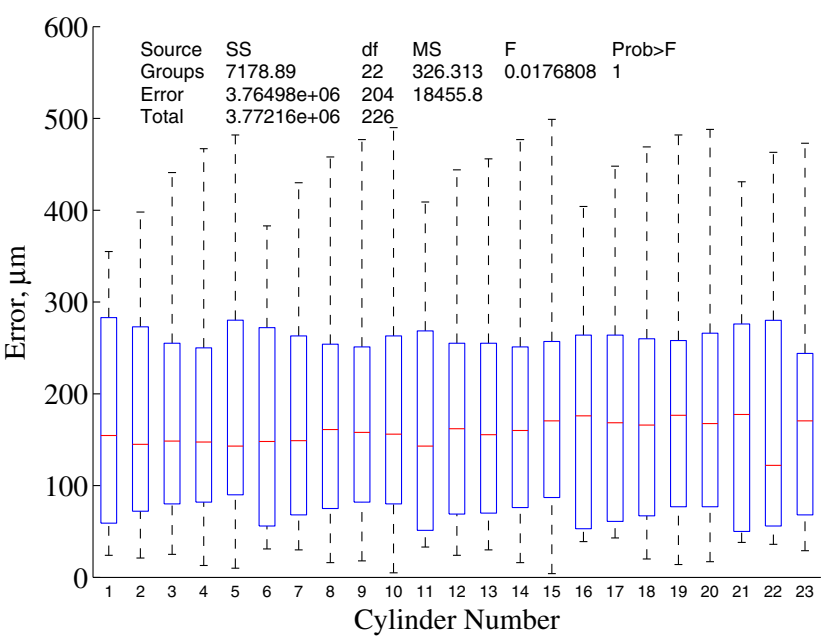

Fig. 14 Individual cylinder error box plot 


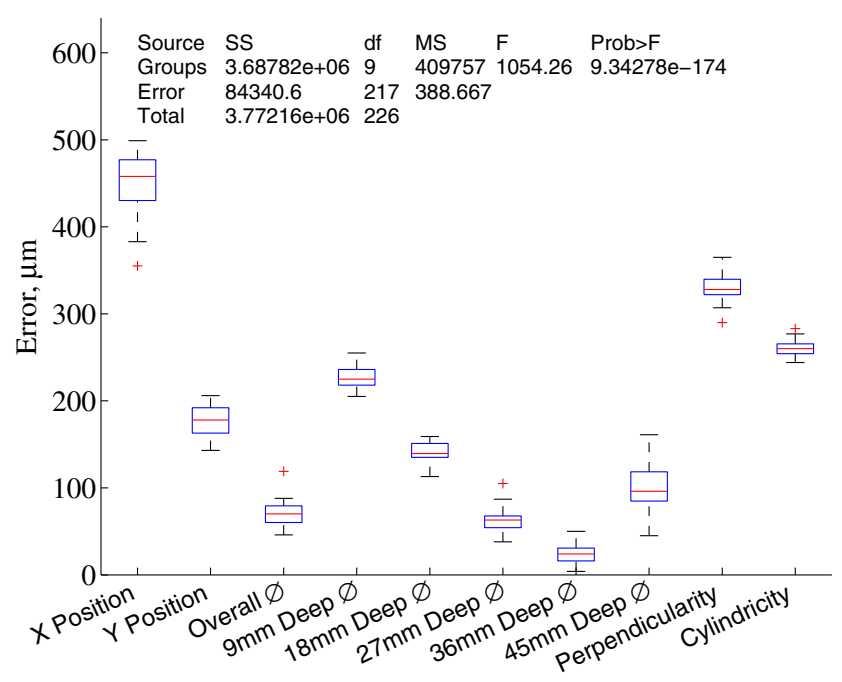

Fig. 15 Cylinder geometry error box plot

Significant variation between feature error levels is explained in the initial literature review in Section 1 as being due to varying static errors and dynamic stiffness across the robot's working envelope. ISO 22514-3 suggests assessing variation between multiple groups using the ANOVA technique, as plotted in Figs. 14 and 15.

A statistically significant difference between error means for each feature inspected is confirmed but not for each cylinder. Insights into the robot and set-up issues can be gained from feature-specific errors. $X$-, $Y$ - and $Z$-axis problem areas are identified from the positional and cylindricity error levels and the change in diameter error over pocket depths. Nevertheless, at 9-36-mm depths, pocket diameters have a decreasing trend. This trend may be due to the tool path geometry, which meant that the most shallow cylinder wall sections were re-cut more times than the deeper

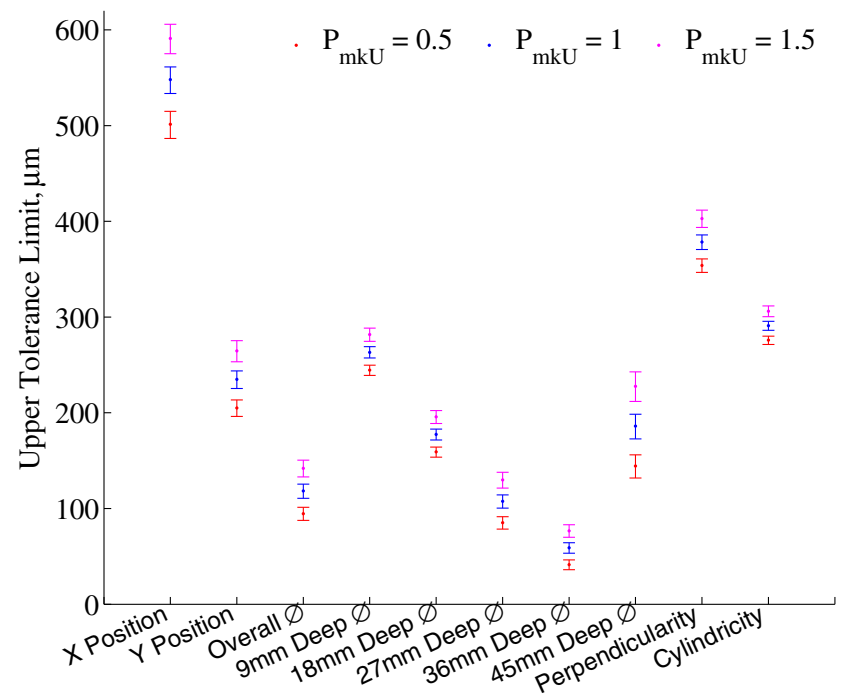

Fig. 16 Cylinder error performance indices

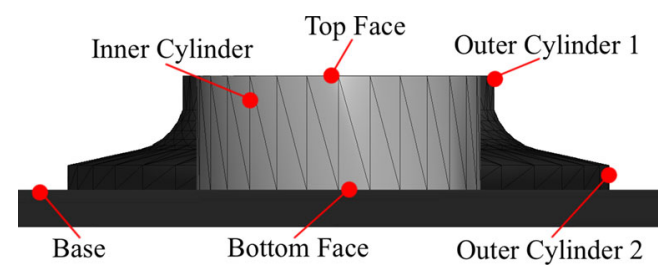

Fig. 17 Nozzle cross section

ones. A relatively high perpendicularity value potentially suggests part relaxation after clamp release, which may help to explain $X$ position errors. Note that the $X$-axis positional errors only have cylinder 21 and 25 outliers removed for the reasons mentioned.

In Fig. 16, the upper tolerance limits at which key levels of performance are achieved are plotted for each feature investigated with confidence intervals. Results were found by computing performances indices for a range of upper tolerances limits and then looking up the tolerance corresponding to key index levels. The associated confidence intervals are converted into upper and lower tolerance bounds by using them to search the dataset of indices originally computed once again. The reference index levels chosen correspond to $6.68 \%, 0.13 \%$ and $3.4 \times 10^{-6} \%$ of robot-machined features exceeding the upper tolerance limit at a $95 \%$ confidence level, when $P_{\mathrm{mkU}}$ is equal to $0.5,1.0$ and 1.5 , respectively.

The best performance is achieved when machining cylindrical geometry at a $36-\mathrm{mm}$ depth as $\sim 100-\mu \mathrm{m}$ upper tolerance is met, although this is not achieved at other depths. The poorest performance is achieved for cylinder $X$ axis position, which has the greatest percentage of errors predicted at $>600 \mu \mathrm{m}$. Systematic error variation between features highlights that errors can be measured and offset, which is worthy of investigation to achieve high-tolerance flexibility in low-cost robotic machining.

\subsection{Nozzle machining trials}

When machining the Nozzle Test Artefact, practical challenges meant that error data derived from weld preparations

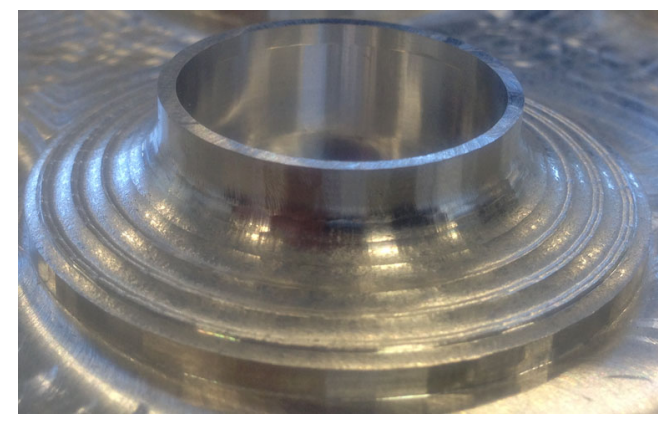

Fig. 18 Machined nozzle 


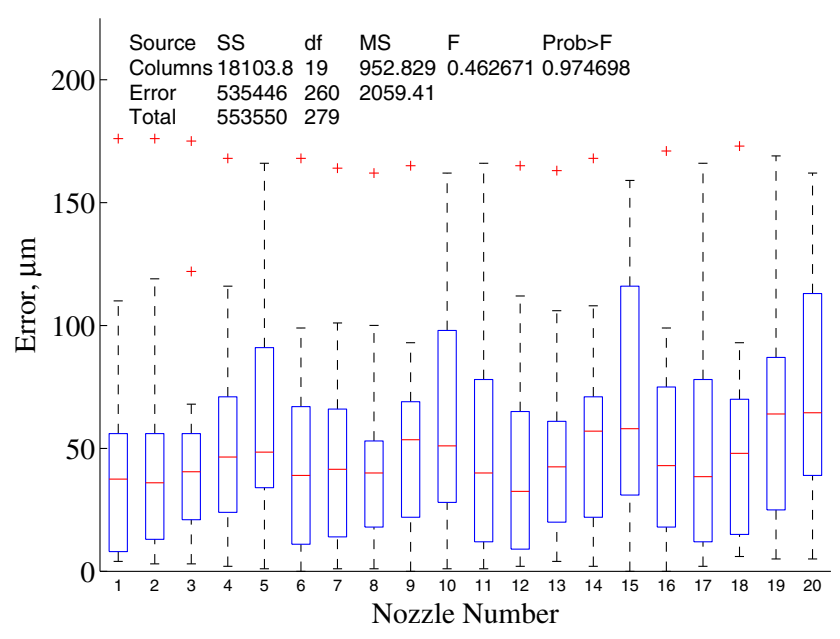

Fig. 19 Individual nozzle error box plot

could not be gained. This is because geometry could not be reliably fitted to inspection points probed on the angled plane and radius on each nozzle due to the machined surface being of insufficient quality. In Figs. 17 and 18, it can be seen that, rather than achieving smooth surfaces, these are wave-like due to the limited resolution of the axial and radial cut depths.

A consequence of using low-cost industrial robotics for machining is imperfect interfacing between the CAM system and robot, making five-axis machining unavailable and reliance on high-resolution three-axis motion necessary for weld preparations. This restricts quality because programmes become impractically long when a resolution is reached that creates the smooth surface desired. Long programmes are problematic due to the lack of controller drip feeding capability. This could be alleviated by calling

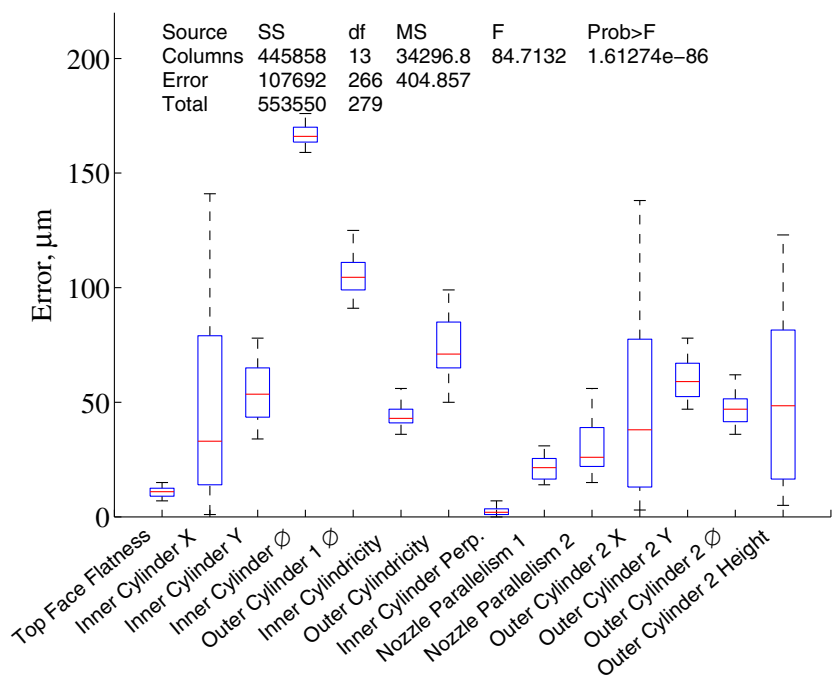

Fig. 20 Nozzle geometry error box plot

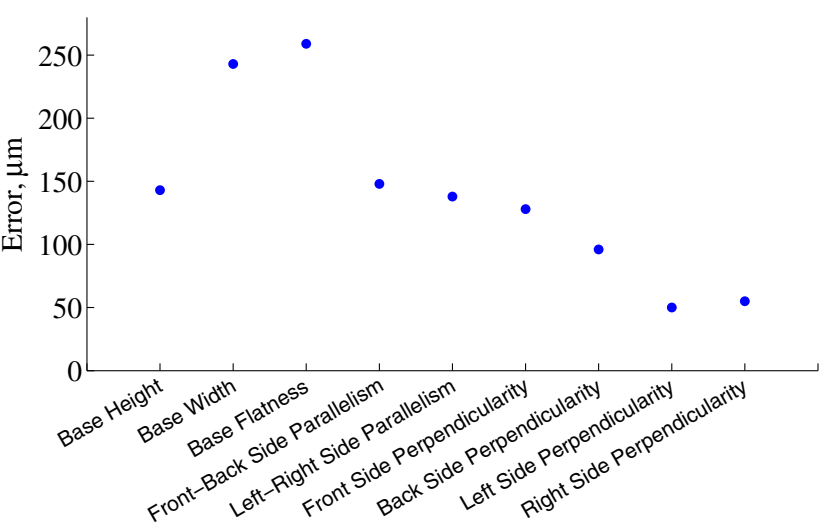

Fig. 21 Overall nozzle artefact errors

canned cycles stored on the controller for interpolation, as in conventional machining programmed in G-Code.

Despite practical challenges other useful data was gained for performance index computation. A significant difference is observed between feature error means but not between nozzle error means, as shown in Figs. 19 and 20 where nozzle and feature data is plotted in machining order. Dimensions are taken in reference to Fig. 17. Inner cylinder perpendicularity is measured with the base plane as the datum. Nozzle parallelism measurements 1 and 2 are taken between the nozzle top and bottom faces and the bottom face and the base, respectively. Error levels measured in the Nozzle Test Artefact are lower than those in the Cylindrical Pocket Test Artefact, which could be explained by various factors, e.g. less operator intervention and differences in geometry and tooling.

The lowest error levels are found for flatness, perpendicularity and parallelism, indicating that the robot $Z$-axis is repeatable and all axes are square. However, $Z$-axis capability could be questioned due to depth and height errors.

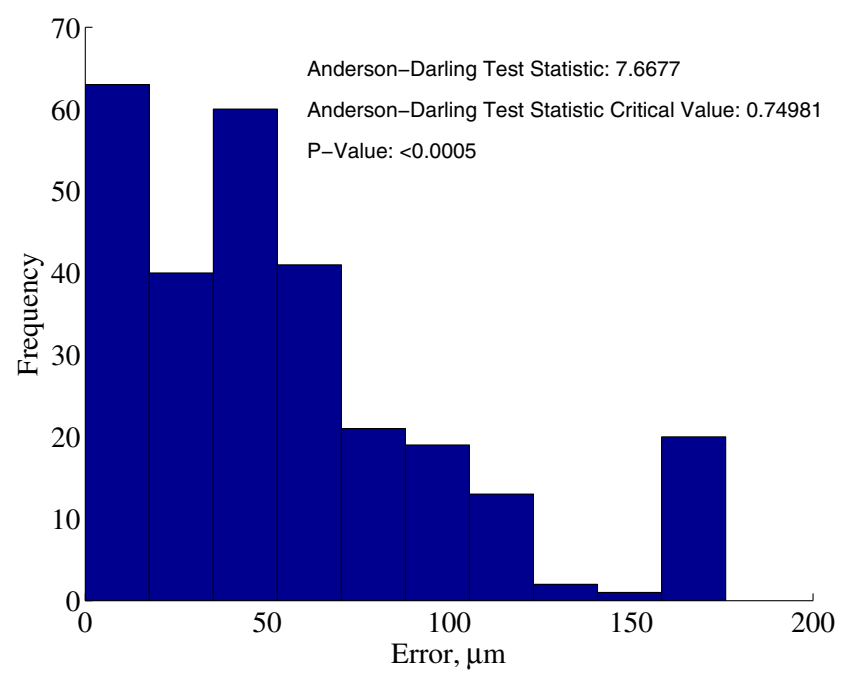

Fig. 22 Nozzle artefact feature error histogram 


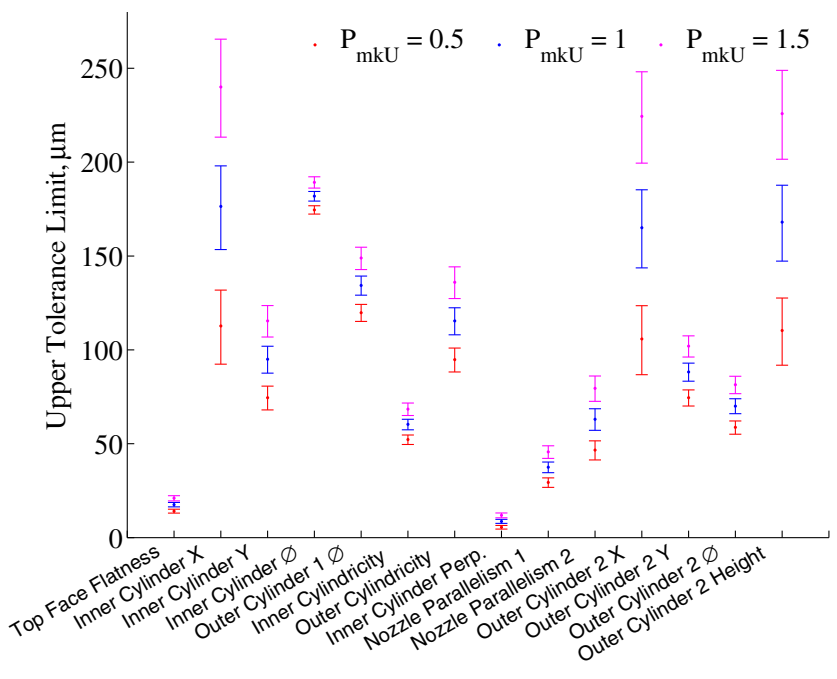

Fig. 23 Nozzle error performance indices

As with the Cylindrical Pocket Test Artefact, $X$-axis errors are shown to be a relatively large proportion of total error in comparison to the $Y$-axis, which may be reflected in the smaller cylinder diameter and cylindricity errors. This appears to be less prominent in the outer cylinder diameter error. Nevertheless, a key observation is that most errors are systematic and therefore able to be offset, if robustly measured in situ with machining, despite complex underlying root causes.

Additionally, overall artefact feature errors are plotted in Fig. 21. These are not included in performance index computation as they are not repeated, and are too few to give a robust insight into generic abilities in the same way as the NAS 979 Machine Tool Test Artefact, but they do suggest some observations may be misleading. This is because the overall flatness of the base, i.e. the area between the nozzles, is $>10$ times the individual nozzle faces maximum flatness error. This shows that, whilst a high flatness tolerance may be achievable over a small area, it is less achievable on a larger scale, which is likely to be due to $Z$-axis repeatability over the working envelope. Parallelism between base sides and perpendicularity, with the base surface face plane, suggest that axes are only square within a range of $\sim 100 \mu \mathrm{m}$.

Results show overall lack of statistical control and nonnormality due to stepped error variation between features rather than a uniform error level across the whole part or nozzle, as expected and validated by Fig. 22. Invalidation of prerequisite assumptions justifies performance index computation on a feature by feature basis rather than per nozzle. This is confirmed with hypothesis tests that indicate normality of data for each feature.

In Fig. 23, the upper tolerance limits at key performance levels are plotted with confidence intervals for each feature considered. Again, the reference index levels chosen correspond to $6.68 \%, 0.13 \%$ and $3.4 \times 10^{-6} \%$ of features exceeding the upper tolerance limit at a $95 \%$ confidence level, when $P_{\mathrm{mkU}}$ is equal to $0.5,1.0$ and 1.5 , respectively. In contrast to the Cylindrical Pocket Test Artefact, better performance at lower tolerance limits is observed. Flatness and perpendicularity achieving upper tolerances limits $<25 \mu \mathrm{m}$ and worst case results for $X$ positions and cylinder height being $<280 \mu \mathrm{m}$ at $P_{\mathrm{mkU}}=1.5$. Error variation between features and artefacts, once again, highlights inconsistent performance but the systematic nature gives evidence that this problem can be solved with compensation.

\section{Summary and conclusions}

Experiments have been conducted to quantify the performance of a Fanuc F200iB hexapod-format robotic machine tool to expand on available literature by determining what the well-documented robotic machining challenges mean in terms of achievable tolerances. The investigation considered three machined artefacts to determine the likelihood of conformance to upper tolerance limits over a range of geometric features. This has provided a substantial body of data and analysis that are useful for comparing technology improvements against.

Error variation is found in the sub-millimetre range, although, in some cases, upper tolerance limits of $<100 \mu \mathrm{m}$ are achieved. Most importantly, it is confirmed that a large proportion of machining errors observed are systematic in nature. Whilst this is well known for robots used in conventional 'pick-and-place' applications, it is not obvious from previously available literature for machining applications where the underlying causes of error are far more complicated and less understood. This result is significant because it gives evidence that compensation can be reliably applied to offset these errors and therefore increase the range of industrial feature machining operations that low-cost hexapod robotics could be applied to. There is a large scope for compensation as currently observed systematic errors can be as high as $\sim 400 \mu \mathrm{m}$.

Practical challenges are also highlighted, although machining harder materials is likely to cause greater tool deflection and therefore greater errors than reported here. Because of the complexity of error contributors and their interactions, as described in the initial literature review, and the challenges associated with fully understanding them for static and dynamic calibration purposes, it is proposed that further research aimed at error reduction should focus on insitu total error monitoring and compensation. It is therefore concluded that metrology-assisted robotic machining techniques should be developed as a means of reducing variation and achieving the maximum benefits of the machining with industrial hexapod robots. 
Overall, base case performance has been quantified to determine how commonly researched robotic machining challenges ultimately relate to achievable tolerances forming a benchmark for process selection and comparing developments against. Potential for substantially tolerance improvement has been demonstrated, directing further research.

Acknowledgments The author of this paper would like to acknowledge Rolls-Royce Civil Nuclear and the Engineering and Physical Sciences Research Council for the provision of funding and to the Nuclear AMRC for the access to equipment and technical support. The views expressed in this paper are those of the authors and not necessarily those of the funding bodies or other organisations mentioned.

Open Access This article is distributed under the terms of the Creative Commons Attribution 4.0 International License (http:// creativecommons.org/licenses/by/4.0/), which permits unrestricted use, distribution, and reproduction in any medium, provided you give appropriate credit to the original author(s) and the source, provide a link to the Creative Commons license, and indicate if changes were made.

\section{References}

1. Wang Z, Mastrogiacomo L, Franceschini F, Maropoulos P (2011) Experimental comparison of dynamic tracking performance of iGPS and laser tracker. Int J Adv Manuf Technol 56(1-4):205-213. https://doi.org/10.1007/s00170-011-3166-0

2. Barnfather JD, Goodfellow MJ, Abram TJ (2016) A performance evaluation methodology for robotic machine tools used in large volume manufacturing. Robot Comput-Integr Manuf 37:49-56. https://doi.org/10.1016/j.rcim.2015.06.002

3. Jung J-HH, Choi J-PP, Lee S-JJ (2006) Machining accuracy enhancement by compensating for volumetric errors of a machine tool and on-machine measurement. J Mater Process Technol 174(1-3):56-66. https://doi.org/10.1016/j.jmatprotec.2004.12.014

4. Weill R, Shani B (1991) Assessment of accuracy in relation with geometrical tolerances in robot links. CIRP Ann - Manuf Technol 40(1):395-399. https://doi.org/10.1016/S0007-8506(07)62015-0

5. Karimi D, Nategh M (2014) Kinematic nonlinearity analysis in hexapod machine tools. Symmetry Reg Accuracy Workspace Mech Mach Theory 71:115-125. https://doi.org/10.1016/j.mech machtheory.2013.09.007

6. Kanaan D, Wenger P, Chablat D (2007) Kinematics analysis of the parallel module of the VERNE machine. In: 12th ITFoMM World Congress, pp 1-6

7. Bi ZM, Jin Y (2011) Kinematic modeling of Exechon parallel kinematic machine. Robot Comput-Integr Manuf 27(1):186-193. https://doi.org/10.1016/j.rcim.2010.07.006

8. Bi ZM, Wang L (2009) Optimal design of reconfigurable parallel machining systems. Robot Comput-Integr Manuf 25(6):951-961. https://doi.org/10.1016/j.rcim.2009.04.004

9. Agheli M, Nategh M (2009) Identifying the kinematic parameters of hexapod machine tool. World Acad Sci Eng Technol 52: 380-385

10. Chanal H, Duc E, Hascoët JY, Ray P (2009) Reduction of a parallel kinematics machine tool inverse kinematics model with regard to machining behaviour. Mech Mach Theory 44(7):1371-1385. https://doi.org/10.1016/j.mechmachtheory.2008.11.004
11. Kanaan D, Wenger P, Chablat D (2009) Kinematic analysis of a serial-parallel machine tool. VERNE Mach Mech Mach Theory 44(2):487-498. arXiv:0811.4733, https://doi.org/10.1016/j.mech machtheory.2008.03.002

12. Fassi I, Wiens GJ Multiaxis machining: PKMs and traditional machining centers. J Manuf Process 2 1. https://doi.org/10.1016/ S1526-6125(00)70008-9

13. Halaj M, Kureková E (2009) Positioning accuracy of nonconventional production machines-an introduction. In: Proceedings of XIX IMEKO World Congress, Lisbon, pp 2099-2102

14. Zhang HZH, Wang JWJ, Zhang G, Gan ZGZ, Pan ZPZ, Cui HCH, Zhu ZZZ (2005) Machining with flexible manipulator: toward improving robotic machining performance. Proc 2005 IEEE/ASME Int Conf Adv Intell Mechatron 0:1127-1132. https://doi.org/10.1109/AIM.2005.1511161

15. Doukas C, Pandremenos J, Stavropoulos P, Foteinopoulos P, Chryssolouris G, Mourtzis D, Stavropoulos P, Foteinopoulos P, Chryssolouris G (2012) On an empirical investigation of the structural behavior of robots. 45th CIRP Conf Manuf Syst 3:501-506. https://doi.org/10.1016/j.procir.2012.07.086

16. Pandremenos J, Doukas C, Stavropoulos P, Chryssolouris G (2011) Machining with robots: a critical review. In: (DET2011), 7 th international conference on digital enterprise technology, Athens, Greece, pp 614-621. ISBN 978-960-88104-2-6

17. Dumas C, Caro S, Garnier S, Furet B (2011) Joint stiffness identification of six-revolute industrial serial robots. Robot ComputIntegr Manuf 27(4):881-888. https://doi.org/10.1016/j.rcim.2011. 02.003

18. Sörnmo O, Olofsson B, Robertsson A, Johansson R (2012) Increasing time-efficiency and accuracy of robotic machining processes using model-based adaptive force control. 10th IFAC Symp Robot Control - SYROCO 2012 45(22):543-548. https://doi.org/10.3182/20120905-3-HR-2030.00065

19. Matsuoka SI, Shimizu K, Yamazaki N, Oki Y (1999) Highspeed end milling of an articulated robot and its characteristics. J Mater Process Technol 95(1-3):83-89. https://doi.org/10.1016/ S0924-0136(99)00315-5

20. Lehmann C, Halbauer M, Euhus D, Overbeck D (2012) Milling with industrial robots: strategies to reduce and compensate process force induced accuracy influences. IEEE Int Conf Emerg Technol Fact Autom, ETFA 17:1-4. https://doi.org/10.1109/ETFA.20 12.6489741

21. Olofsson B, Sörnmo O, Schneider U, Barho M, Robertsson A, Johansson R (2012) Increasing the accuracy for a piezo-actuated micro manipulator for industrial robots using model-based nonlinear control. 10th IFAC Symp Robot Control - SYROCO 2012 45(22):277-282. https://doi.org/10.3182/20120905-3-HR2030.00116

22. Abele E, Weigold M, Rothenbücher S (2007) Modeling and identification of an industrial robot for machining applications. CIRP Ann - Manuf Technol 56(1):387-390. https://doi.org/10. 1016/j.cirp.2007.05.090

23. Bouzgarrou BC, Fauroux JC, Gogu G, Heerah Y (2004) Rigidity analysis of T3R1 parallel robot with uncoupled kinematics. In: Proceedings of the 35 th international symposium on robotics, no. 5 , international federation of robotics, Paris, pp 5-10

24. Li Y, Liu H, Zhao X, Huang T, Chetwynd DG (2010) Design of a 3-DOF PKM module for large structural component machining. Mech Mach Theory 45(6):941-954. https://doi.org/10.1016/j. mechmachtheory.2010.01.008

25. Wu H, Handroos H, Kovanen J, Rouvinen A, Hannukainen P, Saira T, Jones L (2003) Design of parallel intersector weld/cut robot for machining processes in ITER vacuum vessel. Fusion Eng Des 69(1-4):327-331. https://doi.org/10.1016/S0920-3796 (03)00066-8 
26. Wu H, Handroos H, Pessi P, Kilkki J, Jones L (2005) Development and control towards a parallel water hydraulic weld/cut robot for machining processes in ITER vacuum vessel. Fusion Eng Des 7579:625-631. https://doi.org/10.1016/j.fusengdes.2005.06.304

27. Pessi P, Wu H, Handroos H, Jones L (2007) A mobile robot with parallel kinematics to meet the requirements for assembling and machining the ITER vacuum vessel. Fusion Eng Des 82 (15-24):2047-2054. https://doi.org/10.1016/j.fusengdes.2007.06. 012

28. Pan Z, Zhang H (2009) Improving robotic machining accuracy by real-time compensation. In: ICROS-SICE International Joint Conference, pp 4289-4294

29. Pan Z, Zhang H, Zhu Z, Wang J (2006) Chatter analysis of robotic machining process. J Mater Process Technol 173(3):301-309. https://doi.org/10.1016/j.jmatprotec.2005.11.033

30. Olabi A, Béarée R, Gibaru O, Damak M (2010) Feedrate planning for machining with industrial six-axis robots. Control Eng Pract 18(5):471-482. https://doi.org/10.1016/j.conengprac.2010.01.004

31. Turek P, Jȩdrzejewski J, Modrzycki W (2010) Methods of machine tool error compensation. J Mach Eng 10(4):5-25. https://doi.org/ 10.1016/j.procir.2013.06.078

32. Gong C, Yuan J, Ni J (2000) Nongeometric error identification and compensation for robotic system by inverse calibration. Int J Mach Tools Manuf 40(14):2119-2137. https://doi.org/10. 1016/S0890-6955(00)00023-7

33. Kamrani AK, Wei C-CC, Wiebe HA, Wei C-CC (1995) Animated simulation of robot process capability. Integr Manuf Syst 28(1):23-41. https://doi.org/10.1108/09576069410056723

34. Antunes Simões JFCP, Coole TJ, Cheshire DG, Pires AR (2003) Analysis of multi-axis milling in an anthropomorphic robot, using the design of experiments methodology. J Mater Process Technol 135(2-3 SPEC.):235-241. https://doi.org/10.1016/ S0924-0136(02)00908-1

35. Olabi A, Bearee R, Nyiri E, Gibaru O (2010) Enhanced trajectory planning for machining with industrial six-axis robots. Proc IEEE Int Conf Ind Technol 18:500-506. https://doi.org/10. 1109/ICIT.2010.5472749

36. Zargarbashi S, Khan W, Angeles J (2012) The Jacobian condition number as a dexterity index in $6 \mathrm{R}$ machining robots. Robot Comput-Integr Manuf 28(6):694-699. https://doi.org/10.1016/j. rcim.2012.04.004

37. Zargarbashi S, Khan W, Angeles J (2012) Posture optimization in robot-assisted machining operations. Mech Mach Theory 51:7486. https://doi.org/10.1016/j.mechmachtheory.2011.11.017

38. Young K, Pickin CG (2001) Speed accuracy of the modern industrial robot. Ind Robot: Int J 28(3):203-212. https://doi.org/ 10.1108/01439910110389362

39. Chen Y, Dong F (2012) Robot machining: recent development and future research issues. Int J Adv Manuf Technol:1489-1497. https://doi.org/10.1007/s00170-012-4433-4

40. Tunc LT, Barnfather JD (2014) Effects of hexapod robot dynamics in milling. In: 11th International Conference on High Speed Machining, vol 1269. MM Science Journal, Prague, pp 1-8

41. Tunc LT, Shaw J (2015) Experimental study on investigation of dynamics of hexapod robot for mobile machining. Int $\mathbf{J} \mathrm{Adv}$ Manuf Technol 84(5):817-830. https://doi.org/10.1007/s00170015-7600-6

42. Tunc LT, Shaw J (2016) Investigation of the effects of Stewart platform-type industrial robot on stability of robotic milling. Int J Adv Manuf Technol 0:1-11. https://doi.org/10.1007/s00170016-8420-Z

43. ISO 8688-2 (1989) Tool life testing in milling - Part 2: End milling

44. Taylor F (1907) On the art of cutting metals. In: Transactions of ASME, vol 28, New York, pp 1-1198. https://doi.org/10.1038/ scientificamerican01051907-25929bsupp
45. Chen J, Liu W, Deng X, Wu S (2016) Tool life and wear mechanism of WC-5TiC-0.5VC-8Co cemented carbides inserts when machining HT250 gray cast iron. Ceram Int 42(8):10037-10044. https://doi.org/10.1016/j.ceramint.2016.03.107

46. Panda A, Duplák J, Vasilko K (2012) Analysis of cutting tools durability compared with standard ISO 3685. Int J Comput Theory Eng 4(4):621-624. https://doi.org/10.7763/IJCTE.2012.V4.544

47. Tschatsch H (2009) Applied machining technology, Springer, London. arXiv:1011.1669v3, https://doi.org/10.1007/97836420 10071

48. Cheng K (2009) Machining dynamics: fundamentals, applications and practices. Springer, London

49. Davim JP (2011) Machining of hard materials. Springer, London

50. Davim JP (2008) Machining: fundamentals and recent advances. Springer, London

51. Wang J, Zhang H, Pan Z (2016) Machining with flexible manipulators: critical issues and solutions. In: Huat LK (ed) Industrial robots, programming and application, InTech, 2006, Ch. 26, pp 515-526. https://doi.org/10.5772/4914

52. Razali NM, Wah YB (2011) Power comparisons of Shapiro-Wilk, Kolmogorov-Smirnov, Lilliefors and Anderson-Darling tests. J Stat Model Anal 2(1):21-33

53. Stephens MA (1974) EDF statistics for goodness of fit and some comparisons. J Amer Stat Assoc 69(347):730-737. https://doi. org/10.1080/01621459.1974.10480196

54. Stephens MA (1976) Asymptotic results for goodness-of-fit statistics with unknown parameters. Ann Stat 4(2):357-369. https://doi.org/10.1214/aos/1176343411

55. Sakia RM (1992) The box-cox transformation technique: a review. Statistician 41(2): 169. https://doi.org/10.2307/2348250

56. Hosseinifard SZ, Abbasi B, Ahmad S, Abdollahian M (2009) A transformation technique to estimate the process capability index for non-normal processes. Int J Adv Manuf Technol 40:512-517. https://doi.org/10.1007/s00170-008-1376-x

57. Bianchi G, Cagna S, Cau N, Paolucci F (2014) Analysis of vibration damping in machine tools. Procedia CIRP 21:367-372. https://doi.org/10.1016/j.procir.2014.03.158

58. Grossi N, Scippa A, Sallese L, Sato R, Campatelli G (2015) Spindle speed ramp-up test: a novel experimental approach for chatter stability detection. Int J Mach Tools Manuf 89:221-230. https://doi.org/10.1016/j.ijmachtools.2014.11.013

59. Zhang H-TT, Wu Y, He D, Zhao H (2015) Model predictive control to mitigate chatters in milling processes with input constraints. Int J Mach Tools Manuf 91:54-61. https://doi.org/ 10.1016/j.ijmachtools.2015.01.002

60. Moradi H, Vossoughi G, Behzad M, Movahhedy MR (2015) Vibration absorber design to suppress regenerative chatter in nonlinear milling process: application for machining of cantilever plates. Appl Math Modell 39(2):600-620. https://doi.org/ 10.1016/j.apm.2014.06.010

61. Li KM, Liang SY (2007) Modeling of cutting forces in near dry machining under tool wear effect. Int J Mach Tools Manuf 47(78):1292-1301. https://doi.org/10.1016/j.ijmachtools.2006.08.017

62. BSENISO 10360-2 (2009) Geometrical product specificationsacceptance and reverification tests for coordinate measuring machines (CMM) Part 2: CMMs used for measuring linear dimensions

63. AiA/NAS NAS979 (1969) Uniform cutting tests-NAS series metal cutting equipment specifications

64. Gagnol V, Le TP, Ray P (2011) Modal identification of spindletool unit in high-speed machining. Mech Syst Signal Process 25(7):2388-2398. https://doi.org/10.1016/j.ymssp.2011.02.019

65. Zaghbani I, Songmene V (2009) Estimation of machine-tool dynamic parameters during machining operation through operational modal analysis. Int J Mach Tools Manuf 49(12-13):947957. https://doi.org/10.1016/j.ijmachtools.2009.06.010 
66. Li B, Cai H, Mao X, Huang J, Luo B (2013) Estimation of CNC machine-tool dynamic parameters based on random cutting excitation through operational modal analysis. Int J Mach Tools Manuf 71:26-40. https://doi.org/10.1016/j.ijmachtools.2013.04.001

67. Kováŕík M, Sarga L (2014) Process capability indices for non-normal data. WSEAS Trans Business Econ 11:419-429. https://doi.org/10.1080/0898211000896.2614
68. BSISO 22514-3 (2008) Statistical methods in process management capability and performance-part 3: machine performance studies for measured data on discrete parts

69. Barnfather JD, Goodfellow MJ, Abram TJ (2017) Positional capability of a hexapod robot for machining applications. Int J Adv Manuf Technol 89(1):1103-1111. https://doi.org/10.1007/ s00170-016-9051-0 